\title{
Is Ontario adding drug prices to EMRs?
}

\author{
Cite as: CMAJ 2018 May 22;190:E628-9. doi: 10.1503/cmaj.109-5601
}

Posted on cmajnews.com on May 1, 2018.

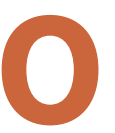

ntario doctors may soon be able to see drug prices on electronic medical records (EMR), but some experts question whether this information will lead to more affordable medications for patients.

Dr. Iris Gorfinkel, a family physician in Toronto, is an advocate for drug-cost transparency. She became frustrated by the difficulty of accessing drug prices, especially as pharmacists called her frequently about patients who couldn't afford medications she prescribed.

According to Gorfinkel, the Ontario Ministry of Health and Long-Term Care may soon require EMR providers to include price information from Ontario's public drug formulary. Ministry contacts have told her that drug transparency is a "top priority." Providing drug-cost information widely in this way would be ground-breaking, said Gorfinkel.

David Jensen, a spokesperson for the ministry, didn't confirm or deny the news. "The province is exploring and prioritizing a large number of potential enhancements to provincial EMR standards, in addition to the inclusion of drug-pricing information," he said.

Gorfinkel hopes for "immediate upfront gains" to patients in the form of lower out-of-pocket costs and improved adherence to medications. "When doctors know drug prices, it will change the con-

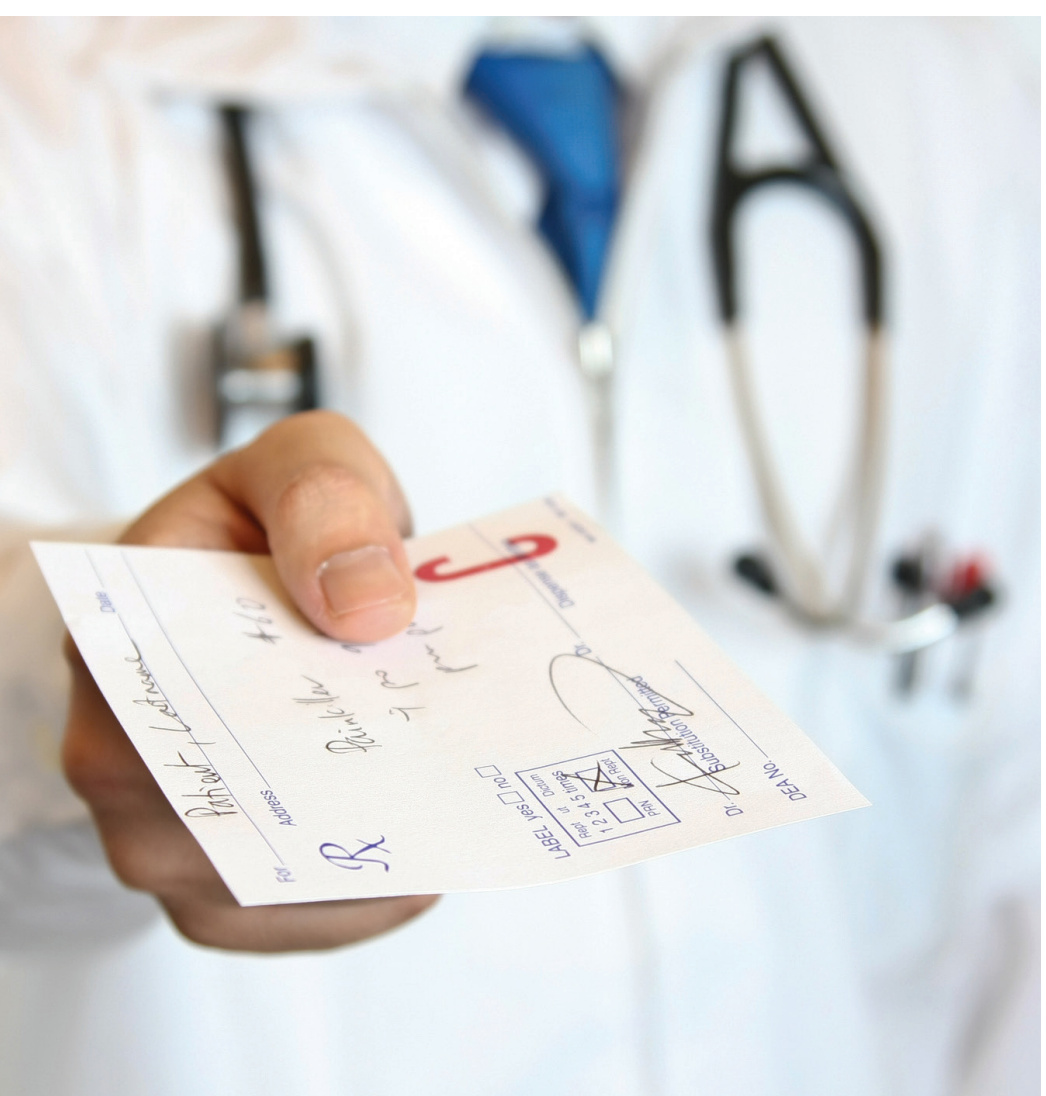

Doctors tend to underestimate the prices of the drugs they prescribe to patients. versation," she said, adding that a longerterm impact could well be lower drug prices.

According to Robyn Tamblyn, scientific director of the Institute of Health Services and Policy Research at the Canadian Institutes for Health Research (CIHR), "research shows that doctors underestimate how much drugs cost." But drug costs are a major factor in patient adherence to medications. A 2015 survey found that one in five Canadian households had members who didn't take a medication prescribed in the previous year due to cost.

The problem with formulary prices, however, is that they aren't the same as the actual prices that provinces negotiate in secret with drug companies. "Increasingly, the list price of a medicine is entirely fictitious," said Steve Morgan, a health services and policy professor at the University of British Columbia. Prices on the public formulary could be $10 \%-50 \%$ higher than those the government actually pays, according to Morgan.

Also, a ballpark price alone isn't likely to change prescribing habits unless accompanied by cost comparisons to other drugs, said Dr. Braden Manns, a nephrologist and health economist in Calgary who studies how costs borne by patients affect chronic disease outcomes. The EMR "needs to make a recommendation for them, like, 'Did you know that drug $X$ is just as effective and it's onesixth the cost?"”

Even then, available evidence does not suggest that physicians respond to comparative drug pricing information as intended. According to Tamblyn of CIHR, research indicates that when physicians know the system is bearing the cost, they tend not to seek lower-cost alternatives. Tamblyn lead a randomized trial on the effects of informing physicians of the out-of-pocket costs to 
patients of various drug options. In the intervention group, $27 \%$ of patients with uncomplicated hypertension were prescribed a diuretic instead of higher-cost options. In the control group, 20\% of patients were prescribed the diuretic. "Surprisingly, the magnitude of the effect was not that great," said Tamblyn, despite potential savings of up to $\$ 1000$ for patients.

"It's the commons problem," said Morgan, citing the economics dilemma of individuals acting in self-interest against a common good. "It's a bit like taking care of the environment, when everyone makes the decision of, 'Oh well, what's the impact of my tiny little action?'”

However, if Ontario does add prices to EMRs, it would allow researchers to study the impact of drug-cost disclosure on an unprecedented scale, and possibly shed light on nudge factors in the context of rising drug costs. "People, on average, are on more medications, and while the prices of medications levelled off for many years, now the medications that are coming out are tending to be more expensive," said Manns.

The move toward drug-cost transparency is also supported by several medical organizations, including the Association of Ontario Health Providers, the Canadian Federation of Nurses Unions, and the Association of Family Health Teams of Ontario. Knowing drug costs would "provide physicians the opportunity to discuss with patients the affordability of the prescription, including exploring whether cheaper alternatives are available," according to a statement by the Ontario Medical Association forwarded to CMAJ.

Wendy Glauser, Toronto, Ont. 